\title{
Practical evaluation of the Figlu test in pregnancy with special reference to the white cell changes
}

\author{
JEAN M. SCOTT AND J. W. SOMMERVILLE \\ From the Research Department, Royal Maternity Hospital, Glasgow
}

SYNOPSIS Using slight modifications to the method of Kohn, Mollin, and Rosenbach (1961) th histidine loading test has been carried out in 210 pregnant women. Seventy per cent. of the cases showed complete haematological correlation and this rose to $87 \%$ when marrow puncture was performed. False positive results occurred in some cases showing active erythropoiesis in response to iron therapy. False negative results were noted when other complications in addition to anaemia were present, and it was felt that these might interfere with the metabolism of histidine. In some cases the histidine test anticipated the haematological change.

Seventy-seven per cent. of women with multiple pregnancies showed evidence of folic acid de ficiency.

Only in a few cases was the test positive before the 25 th week of pregnancy. These were eithefo cases of multiple pregnancy, haemolytic anaemia, malabsorption syndrome, or women with a recent history of megaloblastic anaemia of pregnancy.

The test appears to confirm the significance of white cell changes as an indication of folic acid deficiency in pregnancy.

Recently doubt has arisen about the value of the histidine loading (Figlu) test in the diagnosis of folic acid deficiency during pregnancy. At first the early reports seemed favourable (Hibbard, 1962; Lewis, Moore, and Morris, 1962; Metz, Stevens, and Brandt, 1962), but more recently Chanarin, Rothman, and Watson-Williams (1963) have shown that histidine metabolism may be altered during pregnancy, and, despite existing megaloblastic change, some patients may excrete normal amounts of formimino-glutamic acid (Figlu) after histidine loading. Seven of the English women they studied gave such false negative results, but the test was positive in all but five of 26 Nigerians with megaloblastic anaemia. Regional variations may occur and recent reports confirm this (Husain, Rothman, and Ellis, 1963; Karthigaini, Gnanasundaram, and Baker, 1964). It was therefore thought that our Glasgow figures might be interesting.

\section{METHODS AND MATERIALS}

MEASUREMENT OF FIGLU The method of Kohn et al. (1961) with the modifications described below appeared to improve the electrophoretic run and facilitated the subsequent reading of the test to detect Figlu.

Received for publication 2 October 1964.
One of the early difficulties was the wide variation in the volume of test urine received, which ranged from 90 to $800 \mathrm{ml}$. To overcome this, fluids were restricte in the subjects tested from 9 p.m. the previous evening: This reduced the range to 150 to $500 \mathrm{ml}$., and in order tef iron out any further fluctuations in volume and standardoize the test as much as possible, $0.002 \mathrm{ml}$. per $30 \mathrm{ml}$. volume of test urine was applied to the cellulose acetati strip. For this application a micropipette drawn out to as fine point was used, enabling the operator to form a thin continuous line in the middle of the strip, giving bettep alignment when the paper was cut and making compari son after ammonia treatment easier.

Figlu marker was applied as a thin, but shorter, linê at each outside edge as in the original method, but as pure Figlu is expensive and difficult to obtain in sufficien 5 quantity, strongly positive control urines were substiN tuted. These kept easily for a few months if stored at 2 to $5^{\circ} \mathrm{C}$. with hydrochloric acid and thymol as preservatives.

The concentration of ammonia vapour was anothee variable which could affect the final result. It was found ${ }^{+}$ that this had to be kept high otherwise false negatives might arise. Thus it is advisable to use fresh ammonia fop each test.

For reporting purposes the strips were placed on piece of filter paper over a $60 \mathrm{~W}$. bulb in a bench microscope lamp and graded as follows:-1 Weak positive results could only be seen by this procedure. 2 Positive员 
could be seen in daylight but were more obvious under the test light. 3 Strong positives were easily read in ordinary daylight.

Optimum separation of Figlu and glutamic acid with the tank and power pack used was achieved with a 40min. run at 230 volts using an EEL six-place electrophoresis tank fitted with two cellulose acetate adaptors (EEL) and a Shandon power pack no. 2523.

SUBJECTS STUDIED The results of the test in 210 women were analyzed. Sixteen were in the puerperium. Cases were selected either because they showed haematological signs of folic acid deficiency or had failed to respond adequately to oral or parenteral iron. Women with twin pregnancies were also investigated because of the higher incidence of folic acid deficiency in this group. Nineteen control cases were included, the majority being cases of simple iron-deficiency anaemia.

DIAGNOSTIC CRITERIA The peripheral blood was examined on all patients, buffy coats also where necessary, and in 31 instances marrow puncture was performed. The response to treatment was followed where possible by daily reticulocyte and weekly full blood counts. The haematological assessment was carried out independently and in advance of the Figlu test. The patients were graded as follows:-

Grade I Patients in whom no evidence of megaloblastic change was found in examination of the peripheral blood film or buffy coat.

Grade Ia: Doubtful cases In this group, macrocytosis might or might not be present but there was always marked variation in polymorph size with white cell diameters up to twice normal ( $20 \mu$ or more) and large nuclei with primitive open chromatin network. Such findings, in the absence of a polymorph leucocytosis or any obvious shift to the left with increase in stab cells, immediately aroused suspicion and buffy coats were scanned for at least 10 minutes. If such screening revealed no further white cell changes, the patient was placed in this group.

Grade II Typical white cell changes were found in grade $I I$ subjects, and when typical giant hypersegmented polymorphs were found the case was placed in this group. Three main types of cell were recognized. The most mature showed some condensation of the nuclear chromatin and nuclear hypersegmentation, eight to 12 lobes were frequent, and rosette formations common. The second type had fewer, but slightly larger lobes, approximately six to 10 in number, and was often shaped like a hand of bananas, while the third type was really a giant metamyelocyte and unlike the others was seen more frequently in marrows. As one would expect it was the largest of the three and frequently had a most irregularly shaped nucleus, which reminded one of a Manx sign or a swastika.

Generally only a few of the white cells were so affected and they had to be sought for, but variation is size (grade Ia) was common and immediately aroused suspicion.

Grade III: Transitional or megaloid changes Apart from a few cases, which will be mentioned later, white cell changes as above were found in this group and in addition nucleated red cells of transitional type were seen. Polychromasia was a common finding and Howell Jolly bodies were fairly frequent. Macrocytosis varied, depending on the degree of iron deficiency, but invariably some large, irregularly shaped macrocytes were seen.

Grade IV: Megaloblastic change In addition to the above features typical megaloblasts were found in this group.

This grading roughly follows that of Dawson (1962) except that it has been applied to buffy coats as well as to marrows. In those cases in the present series where any discrepancy arose between the buffy coat and marrow grading, the marrow result was the one accepted.

\section{RESULTS}

Of the 210 patients investigated, 128 (group A) had haematological evidence of megaloblastic change (grade $I I$ or more) and gave a positive histidine loading test (Table I). In 18 the haemoglobin was 10 g. $\%$ or over. The remainder were definitely anaemic and the lowest value recorded was $5.5 \mathrm{~g}$. \%. The individual results were collated and are shown in Table II. It can be seen that no correlation existed between the extent of haematological change and the amount of formimino-glutamic acid in the urine.

TABLE I

\begin{tabular}{|c|c|c|c|c|c|}
\hline & & ANAI & s of 210 & ASES & \\
\hline Group & & $\begin{array}{c}\text { No. of } \\
\text { Cases }\end{array}$ & $\begin{array}{l}\text { Haema- } \\
\text { tology }\end{array}$ & $\begin{array}{l}\text { Figlu } \\
\text { Test }\end{array}$ & $\begin{array}{l}\text { Percentage } \\
\text { Incidence }\end{array}$ \\
\hline Correlation & $\mathbf{A}$ & 128 & + & + & \\
\hline complete & $\mathbf{B}$ & 19 & - & - & 70 \\
\hline No correla- & $\mathbf{C}$ & 7 & + & - & \\
\hline tion & & 17 & - & + & $11 \cdot 4$ \\
\hline Doubtful & D & 15 & $?$ & - & \\
\hline & & 24 & $?$ & + & $18 \cdot 6$ \\
\hline
\end{tabular}

TABLE II

HAEMATOLOGICAL GRADING

\begin{tabular}{lrrrr} 
Figlu & \multicolumn{2}{l}{ Grade } & & \\
\cline { 2 - 5 } Test & Ia & II & III & IV \\
\hline Weak positive & 4 & 6 & 4 & 12 \\
Positive & 17 & 33 & 21 & 26 \\
Strong positive & 3 & 13 & 8 & 5 \\
Totals & 24 & 52 & 33 & 43
\end{tabular}

The second group (group B, Table I) consisted of 19 patients with no haematological evidence of folic acid deficiency and negative Figlu tests. Thirteen were cases of simple iron-deficiency anaemia. The remainder, who were selected at random, had been admitted to the antenatal wards for obstetrical reasons. Thus of the 210 women investigated, 147 or $70 \%$ showed complete haematological and biochemical correlation.

In 24 or $11.4 \%$ of the remainder there was no correlation (group C, Table I). In seven haemato- 
logical evidence of megaloblastic change (grade $I I$ or more) was present but the Figlu test was negative. Unfortunately each pregnancy was further complicated (oedema and hypoproteinaemia 2, pre-eclamptic toxaemia 2 , cardiac disease 1 , pyelitis 1 , and recent abnormal delivery 1) and folic acid therapy had to be given. In the other 17 patients in this group the Figlu test was positive in the absence of any haematological change, other than that of iron deficiency. On review two might have been placed in grade $I a$; a third patient showed typical white cell changes on the sixth day of treatment with folic acid and a fourth, who was only 22 weeks pregnant, had had five previous megaloblastic anaemias of pregnancy. It seems possible that the Figlu test was correct in these four instances. Eight others were all near term and were given folic acid as well as iron. In their case it was impossible to come to any conclusion, but the remaining five patients were interesting. All were in a regenerative phase with evidence of active erythropoiesis and raised reticulocyte count when the Figlu test was done. Four were responding to parenteral iron and one to blood loss. Her marrow was normoblastic. Folic acid was therefore withheld and all continued to respond to iron alone.

The last group (group D, Table I) includes all patients with doubtful haematological change (grade Ia). A separate analysis of these cases was made because it was felt that the haematological change was less specific and the grading arbitrary. Fifteen of the patients had negative Figlu tests and all responded to iron alone except for one who was inadvertently given folic acid. The remaining 24 patients had positive Figlu tests, as shown in Table II. They were given folic acid and showed a reticulocyte response with subsequent rise in haemoglobin. Another eight patients were in this group originally, but after marrow examination four were found to be showing megaloblastic change and the remainder became megaloblastic while under observation. They were therefore included in group A.

EFFECTS OF MULTIPLE PREGNANCY In all 33 cases of multiple pregnancy were examined. Thirty-four Figlu tests were carried out on these patients. One, which was negative initially, became positive six weeks later. Unfortunately in two cases the blood results were not available. Altogether $77 \%$ of the tests were positive. The results are shown in Table III. Thus in 32 tests, where comparison was possible, $78 \%$ showed good haematological correlation.

STAGE OF PREGNANCY Most of the cases were diagnosed during the last trimester. Only three patients had a positive Figlu test before the 25th
TABLE III

RESULTS OF 32 TESTS IN MULTIPLE PREGNANCIES

\begin{tabular}{rcc} 
Test No. & Haematology & Figlu Test \\
\hline 21 & + & + \\
4 & - & - \\
4 & + & - \\
3 & \% correlation $=78$ & +
\end{tabular}

week. Two of these women had had megaloblastite anaemia in at least two pregnancies and the third patient, who was found to have triplets, had $\overrightarrow{\mathrm{an}}$ occasional megaloblast and many intermediate mes: aloblasts in her marrow.

VALUE OF THE MARROW SMEAR In the early part of the survey the marrow was examined whenev possible in order to obtain a complete picture, but eventually this examination was dispensed with the buffy coat gave almost as good results and was less painful for the patient. Thirty-one marrows werde examined. In 21 of these the buffy coat or blood film had only shown white cell changes, but on marros examination occasional megaloblasts or transitionel cells were found. In seven other cases both blood and marrow gradings were the same. Hence in onfy three instances had the actual diagnosis to altered after marrow puncture. Two buffy coats hool been grade $I$ but marrow examination placed the patients in grades $I I$ and $I I I$. The third case had been considered as grade II on buffy coat screening, bitt no evidence to support this was found in the marrow. When these corrected results were compared wi the Figlu test an $87 \%$ correlation was obtained (Table IV).

\section{TABLE IV}

RESULTS IN 31 MARROW EXAMINATIONS

\begin{tabular}{|c|c|c|}
\hline Test No. & Marrow & Figlu Test \\
\hline 26 & + & + \\
\hline 1 & - & - \\
\hline 1 & - & + \\
\hline 3 & $\%$ corre & - \\
\hline
\end{tabular}

THE WHITE CELL ANOMALY The finding of giafie hypersegmented polymorphs in the peripheral bloo is generally accepted as one of the earliest signs megaloblastic change in pregnancy, and this ws certainly true here except in some cases where the megaloblastic change only became apparent after iron therapy. There were 26 such cases of apparent simple iron-deficiency anaemia, which after pare teral iron showed evidence of megaloblastic change In half of these no typical giant hypersegmente polymorphs were seen. Yet three were frankhy 
megaloblastic and 10 were of transitional type (grade III). Diagnosis in the latter instance was by no means easy. Polymorph lobe counts were of little value and showed no significant change, presumably because of the initial marked iron deficiency and the raised count generally associated with this. However, a history of unexplained failure to respond adequately to parenteral iron and the finding of Howell Jolly bodies and blue polychromasia with low reticulocyte count were helpful.

THE EARLY POSITIVE TEST It is possible for the Figlu test to be positive in advance of any haematological change. This was found in four patients in group A, in whom treatment was withheld until haematological confirmation was obtained. There were also other patients in group $\mathrm{C}$ who were given folic acid, but might well have shown this phenomenon. Indeed one patient actually developed white cell changes in course of treatment with folic acid.

\section{DISCUSSION}

Since the histidine loading test is at best only a tolerance test, one would be ill advised to expect it to produce anything like complete accuracy. It has its limitations, especially if one chooses a qualitative method such as that of Kohn et al. (1961). Nonetheless, if a few modifications, such as allowing for variation in urinary output, are applied to this relatively simple procedure, quite a remarkably high degree of haematological correlation can be achieved and this increases to $87 \%$ after marrow examination.

False negatives may also arise, but in our experience not so frequently as Chanarin et al. (1963) state. They reported a $47 \%$ incidence in their English patients and felt that this was due to alterations in histidine metabolism which occurred in the gravid state and rendered the test unsatisfactory during pregnancy. However, this did not hold true to the same extent in their Nigerian patients, where $81 \%$ of women with megaloblastic anaemia had a positive Figlu test. Though they were unable to offer any real explanation for this difference, Chanarin and his colleagues felt that it might be related to the greater degree of folic acid deficiency in Nigerian women. Obviously a population variable exists (Hibbard, 1962; Lewis et al., 1962; Metz et al., 1962; Husain et al., 1963; Karthigaini et al., 1964), and surprisingly enough the Glasgow results are nearer those of the Nigerian patients. However, it does not necessarily follow that folic acid deficiency is greater here. Indeed in the present series there was no correlation between the amount of formimino-glutamic acid excreted and the degree of haematological change found. It may be that other deficiencies, including that of vitamin $\mathbf{B}_{12}$ (Kershaw and Girdwood, 1964), either directly or indirectly through their influence on folic acid, affect the metabolism of histidine.

In the present series it is of additional interest to note that false negatives were found in cases which were otherwise complicated and one wonders whether these additional factors may in their own way have affected histidine metabolism and the excretion of formimino-glutamic acid. It would be interesting to know if additional complications were frequent in the series reported by Chanarin et al. (1963).

One or two further points of interest have arisen from the present survey, for instance, the high incidence of folic acid deficiency in multiple pregnancy. It is certainly well known that megaloblastic anaemia is commoner in twin pregnancies (Thompson and Ungley, 1951; Scott, 1956; Giles and Shuttleworth, 1958) but it is probably not fully appreciated that minor degrees of this condition are so frequent. Recently Ball and Giles (1964) have shown that the serum folic acid levels are also significantly lower. Indeed the range overlapped that found in megaloblastic anaemia. In the present series there was a $77 \%$ incidence of positive Figlu tests in twin pregnancies.

Where the Figlu test is positive before the 25th week the question of multiple pregnancy has to be considered, especially if the patient is a primigravida and gives no history of previous megaloblastic anaemia of pregnancy. The malabsorption syndrome is also a possibility and we have recently noticed that patients with haemolytic anaemia tend to have an early positive test. They frequently also fail to show the usual white cell changes, like 13 other anaemic patients in the series who developed megaloblastic change after parenteral iron therapy. It is difficult to understand why this should happen. One possibility is that increased erythropoietic activity occurring in both conditions may pinpoint the deficiency in the red cell series first and so alter the normal sequence of events. In this respect it is interesting to note that cases of post-haemorrhagic anaemia occasionally show similar findings.

In view of these findings it was suggested that a primigravida, whom we saw recently with a grade $I I$ buffy coat and a positive Figlu test at 20 weeks, might either have a multiple pregnancy or be a case of the malabsorption syndrome. On further investigation she proved to belong to the latter group.

These cases are, however, the exception and in most instances early megaloblastic change can be recognized in the peripheral blood on the basis of the white cell appearances alone. Mere variation in 
size (grade $I a$ ) as a single feature should not be overstressed, as happened in 15 cases here, but neither can its presence be neglected, since another 32 patients had positive Figlu tests, eight of them eventually proving megaloblastic. Indeed it is in this doubtful group that we now find the Figlu test to be of most use. Otherwise, in the majority of cases it only serves to confirm the significance of giant hypersegmented polymorphs, and, once one recognizes the importance of these cells, treatment can be started at an earlier stage. Thus fewer frank megaloblastic anaemias are now being seen, and in this hospital, the majority only in unbooked cases.

We should like to thank Dr A. D. T. Govan, Director of Research, for his advice and encouragement in the preparation of this paper and to our clinical colleagezess, whose cooperation made the work possible.

\section{REFERENCES}

Ball, E. W., and Giles C. (1964). J. clin. Path., 17, 165.

Chanarin, I., Rothman, D., and Watson-Williams, E. J. (19/3). Lancet, 1, 1068.

Dawson, D. W. (1962). J. Obstet. Gynaec. Brit. Cwlth, 69, 38.

Giles, C., and Shuttleworth, E. M. (1958). Lancet, 2, 1341.

Hibbard, E. D. (1962). J. Obstet. Gynaec. Brit. Cwlth, 69, 739.

Husain, O. A. N., Rothman D., and Ellis L. (1963), Ibid., 70, 821

Karthigaini, S., Gnanasundaram, D., and Baker S. J. (1964). I\$Pd., $71,115$.

Kershaw, P. W., and Girdwood, R. H. (1964). Scot. med. J., 9, 207

Kohn, J., Mollin, D. L., and Rosenbach, L. M. (1961). J. clin. P ght. $14,345$.

Lewis, F. J. W., Moore, G. R., and Morris, B. M. (1962). J. Obsiet. Gynaec. Brit. Cwlth, 69, 742.

Metz, J., Stevens, K., and Brandt, V. (1962). Brit. med. J. 2, 1440.

Scott, J. M. (1956). Brit. med.J., 2, 635.

Thompson, R. B., and Ungley, C. C. (1951). Quart. J. Med., 20, 287 